\title{
Alguns aspectos da biologia floral de Annona sericea Dun. (Annonaceae)
}

\author{
Antonio Carlos Webber ( ${ }^{\text {* }}$ )
}

\section{Resumo}

São apresentados neste trabalho alguns aspectos da biologia floral de Annona sericea Dun. As suas flores apresentam características de cantarofilia e os insetos visitantes são besouros Chrysomelidae (provável polinizador) e moscas Sciaridae (eventualmente polinizador acessório). Os besouros alimentam-se da parte interna das pétalas e também copulam no interior da fior. A temperatura das flores se eleva até $6^{\circ} \mathrm{C}$ além da temperatura ambiente, no período noturno. É mostrado um esquema da queda dos estigmas e posterior descarga do pólen. A flor não pode ser autopolinizada, pois os estigmas caem antes da descarga do pólen, porém ela é autocompativel. A fertilidade polínica é de $96 \%$, todavia o número de frutos formados naturalmente é pequeno.

\section{INTRODUÇÃo}

A biologia floral dos membros da família Annonaceae é ainda pouco estudada e, entre os trabalhos realizados a esse respeito, podemos mencionar os de Van der Pijl (1953), Periasamy (1954) e Gottsberger (1970).

A Amazônia é, segundo Walker (1971), o maior centro de dispersão da família e, nessa região, até o presente, não foram feitos estudos sobre a biologia de nenhuma das espécies que nela ocorrem.

Este tabalho mostra alguns aspectos da biologia floral de Annona sericea Dun., uma espécie que, segundo foi observado, ocorre naturalmente em vegetaçăo secundária.

\section{MATERIAL E MÉTODOS}

O presente estudo foi realizado no Campus do INPA - Manaus, onde a espécie ocorre nas áreas mais iluminadas. As observações foram feitas em cinco indivíduos localizados em diferentes pontos.
As observações iniciaram-se na terceira semana de fevereiro, estendendo-se até à primeira semana de maio de 1979 , nos seguintes horários: das 06:30 às 09:30, 14:00, 17:00 e das $18: 00$ às $05: 30$, sendo em maior número de vezes entre 18:00 e 22:00.

A espécie foi identificada por comparação com material existente no herbário, tendo sido coletada uma amostra, a qual foi incorporada à coleção do INPA ( $A$. Webber 27, INPA 81.336).

Os insetos visitadores foram capturados com auxílio de rede entomológica ou com a mão e estão depositados na coleção entomológica do INPA.

A cor das pétalas das flores e dos botões foi determinada pela tabela de Locquin (1975). As partes da flor que emitem odor foram evidenciadas com vermelho neutro pelo método de Vogel, descrito em Prance \& Arias (1975), e a receptividade dos estigmas foi verificada diretamente ou com auxílio de lupa manual. As temperaturas das flores foram medidas com um termômetro Technoterm tipo digital.

Para testar se as fiores eram autocompatíveis, foram isoladas algumas com sacos de malha de nylon de tamanho reduzido. A polinização artificial foi feita, recolhendo-se pólen de flores, nas quais já havia ocorrido a deiscência das anteras, sendo o pólen transferido no dia em que ocorreu a deiscência ou no dia posterior a este, para o estigma de outras flores que estavam receptivas, no mesmo indivíduo e em indivíduos distintos. Essa transferência foi feita no período da marihã e no período da noite. A deiscência das anteras e a liberação do pólen foram observadas através de uma cavidade feita em uma das pétalas.

A fertilidade polínica foi avaliada, usando-se azul de algodão, conforme o método descrito por Darlington \& La Cour (1965).

(") - Aluno do curso de Pós-Graduaçăo do INPA/FUA na área de Botânica, Bolsista do CNPq. 


\section{Resultados}

As flores de Annona sericea Dun. têm três sépalas reduzidas, três pétalas carnosas (raramente aparecem rudimentos da outra série de pétalas) e numerosos estames, dispostos compactamente ao redor do receptáculo onde estão inseridos os ovários com os estigmas (Fig. 1).

As flores nascem nas extremidades dos ramos, em agregados de três a cinco, as quais não se desenvolvem simultaneamente, sendo que cada ramo produz sucessivos agregados à medida que vai crescendo. Os botões têm coloração esverdeada (S2d) e as flores na época de sua maturidade têm coloração amarela (M6h).

A produção de flores é muito variada de indivíduo para indivíduo, em número de flores e em freqüência de flores em antese. Em alguns indivíduos, há um período de vários dias entre a antese de uma flor e a antese da flor seguinte.

A flor não se abre, sendo que apenas ocorre uma leve separação entre as pétalas, o que se considerou antese. Esta separação das pétalas não é total; os ápices das mesmas permanecem fracamente unidos (Fig. 2).

A antese ocorre na parte da manhã e é gradual, sendo a separação iniciada na parte mediana da pétala continuando depois em direção à base e ao ápice.

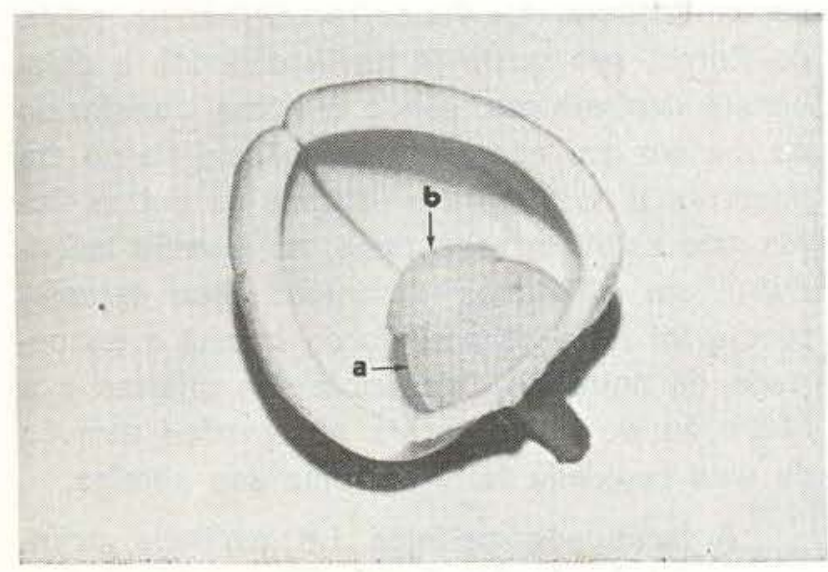

Fig. 1 - Secção da flor de A. sericea Dun. mostrando a disposição dos estames e dos estigmas, (a) estames, (b) estigmas.

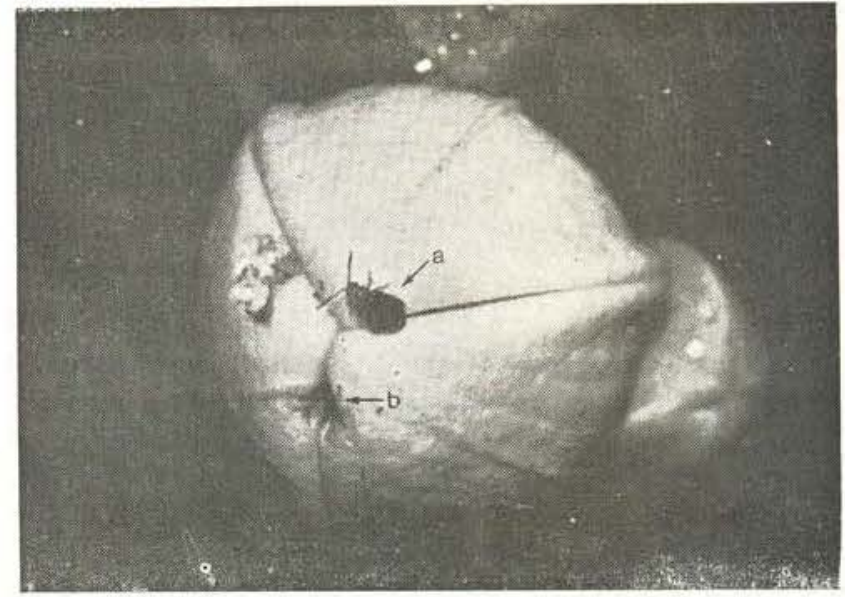

Fig. 2 - Flor de A. sericea Dun. em antese com um besouro visitante e uma escavaçăo feita na mesma. (a) besouro, (b) escavaçăo.

Durante o período noturno do dia em que ocorreu a antese, por volta das 19 horas, a flor começa a ter um aumento de temperatura (Fig. 3) acompanhado por uma produção de odor que lembra clorofórmio ou uma mistura de éter e clorofórmio. A produção de odor ocorre na parte basal interna das pétalas, o que foi constatado pela evidenciação do osmóforo pelo vermelho neutro. A temperatura da flor eleva-se gradativamente até $6^{\circ} \mathrm{C}$ acima da temperatura ambiente; com a elevação da temperatura, ocorre uma intensificação do odor, e, dependendo das condições microclimáticas, este é perceptível para o olfato humano a uma distância de até 1 metro.

A flor é protógina, sendo que a receptividade dos estigmas inicia-se no período de 48 horas antes do desprendimento dos mesmos. Os estigmas quando estão receptivos apresentam em sua superfície uma secreção brilhante e bastante viscosa. Esta secreção é insípida, tornando-se mais abundante quando a temperatura da flor se eleva.

Com a queda do conjunto de estigmas, desencadeia-se a deiscência das anteras, liberação do pólen e, finalmente a queda dos estames.

Os estames normalmente estão firmemente compactados e em posição ligeiramente inclinada. Um afrouxamento dos estames causado pela queda dos estigmas, faz com que os 


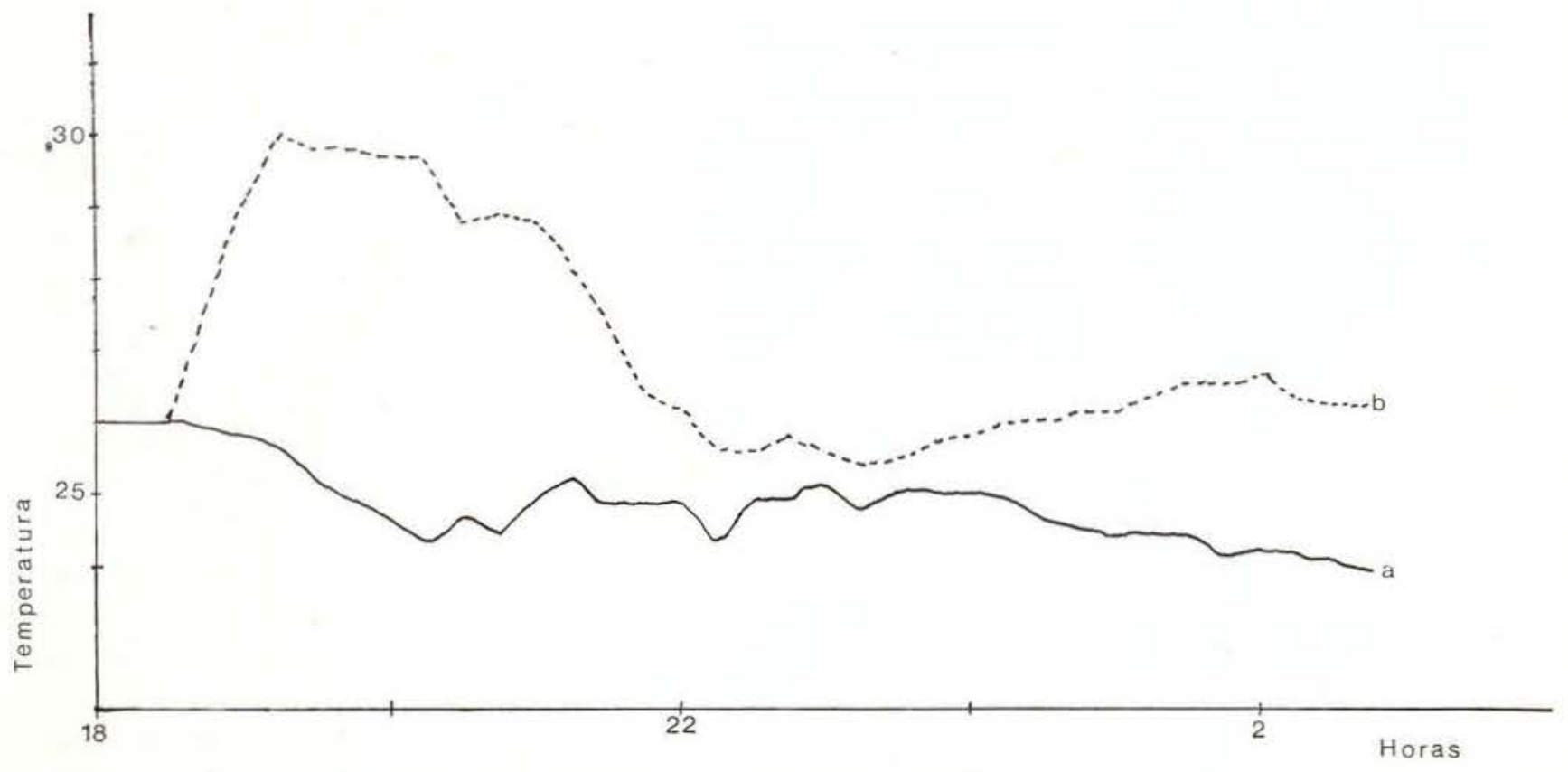

Fig. 3-Gráfico mostrando a variação da temperatura da flor de A. sericea Dun. comparada a temperatura ambiente. (a) temperatura ambiente, (b) temperatura da flor.

mesmos, gradualmente passem à posição vertical, quando ocorre a deiscência das anteras e liberação do pólen (Fig. 4); este se apresenta em tétrades unidas formando um filamento.

Após a liberação do pólen, os estames se desprendem do receptáculo (Fig. 5). Terminado este processo, ocorre a queda das pétalas, sendo que estas caem uma a uma.

O processo de descarga de pólen é simultâneo em todas as flores do mesmo indivíduo e, quando caem os estigmas de uma flor, ao mesmo tempo caem os estigmas de todas as flores que estão em antese neste indivíduo. Entre indivíduos diferentes o horário em que ocorre a queda dos estigmas é diferente. É oportuno notar-se que o horário de queda dos estigmas num mesmo indivíduo é sempre o mesmo em todos os dias.

O intervalo de tempo entre o início da elevação da temperatura até o momento da queda dos estigmas é variado; se este for longo, poderá haver dois picos de temperatura, como pode ser visto na Fig. 3. Quando este intervalo é curto, ocorre somente um pico.
No período da noite, quando o odor se intensifica, a flor é visitada por besouros da família Chrysomelidae e moscas da família Sciaricae.

As moscas por seu tamanho reduzido conseguem entrar na flor por entre as pétalas, andando em todo interior da flor e também na parte externa das pétalas, onde algumas vezes fazem ovoposição.

Os besouros não conseguem entrar na flor naturalmente; penetram fazendo escavações por entre duas pétalas (Fig. 2) e permanecem no interior da flor comendo a porção basal das pétalas até que ocorra a queda das mesmas. Ocasionalmente, os besouros saem antes da queda das pétalas. O número de besouros que entra na flor é variável, tendo sido encontrados até treze numa flor. Repetidas vezes foram vistos besouros copulando no interior da flor. Mesmo com chuva os insetos visitam a flor.

A frutificação foi reduzidíssima, tendo havido a formação de apenas um fruto, em um dos indivíduos, durante o tempo de observação. 


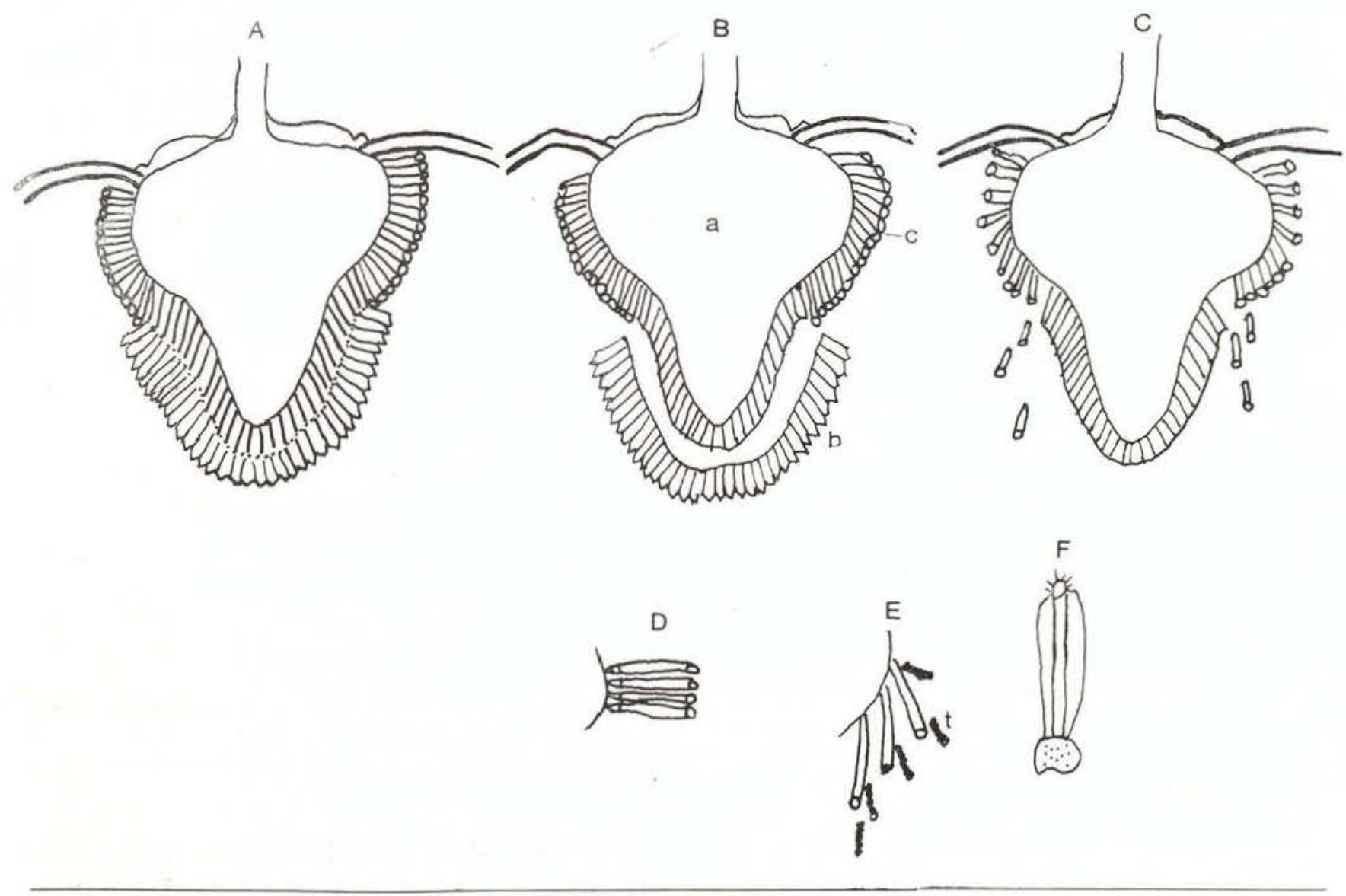

Fig. 4 - Desenho esquemático da secção longitudinal da flor de A. sericea Dun. mostrando: antes da queda dos estigmas (A), a queda dos estigmas (B) e a queda dos estames (C). Detalhes da posição dos estames antes (D) e depois da queda dos estigmas (E). Estame isolado (F). (a) receptáculo, (b) estigmas, (c) estames e (t) coluna de tétrades. A, B e $C$ aumentado 4 vezes aproximadamente $D$ e $E$ aumentado 8 vezes aproximadamente $F$ aumentado 12 vezes aproximadamente.

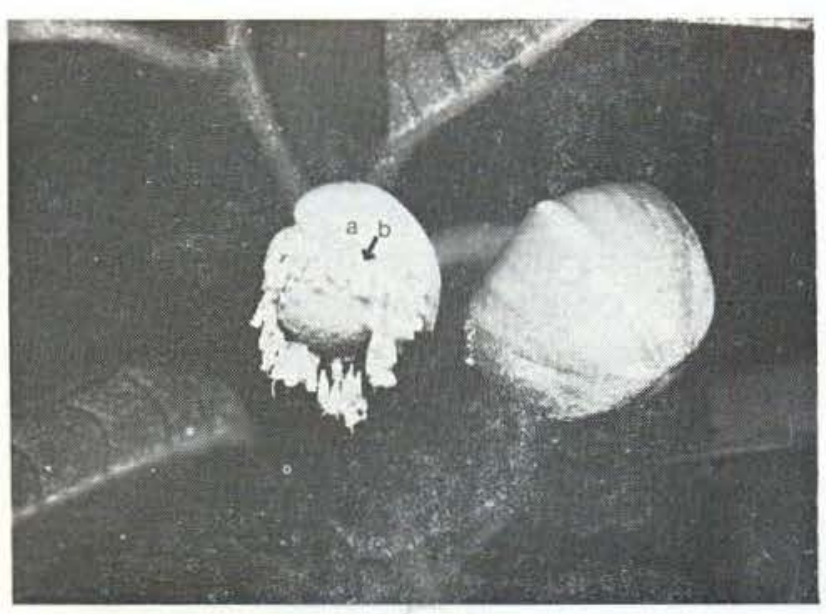

Fig. 5 - Parte da flor que restou após a queda dos estigmas, estames e pétalas com alguns estames aderidos ao receptáculo. (a) receptáculo, (b) estames.
Os testes químicos feitos para avaliar a fertilidade do pólen no dia e um dia após a descarga, mostraram um grau de fertilidade de $96 \%$.

Nas flores que sofreram polinização artificial, foi possível notar-se o início do crescimento dos carpelos, após quatro dias em média.

A polinização artificial resultou na forma. ção de frutos na sua totalidade ainda que o pólen fosse da mesma planta.

\section{DISCUSSÃo}

As flores de Annona sericea Dun, não podem ser autopolinizadas, pelo fato de os estigmas cairem antes da descarga do pólen, em- 
bora a espécie seja autocompatível, i.e. o pólen de uma flor pode fertilizar outra flor no mesmo indivíduo. Isto indica que o processo de polinização necessita ser mediado por um agente externo.

Periasamy (1954) observou em Cananga odorata Hook. f. (Annonaceae) a queda do conjunto de estigmas decorrente da descarga dos estames. Já em Annona sericea Dun. observou-se que a queda dos estigmas é o que favorece a descarga dos estames.

$\mathrm{O}$ fato de cada indivíduo ter a descarga do pólen sempre no mesmo horário, ainda que em dias diferentes, em todas as flores que estão em antese e horários diferentes para indivíduos distintos, deve ser regido por um sistema fisiológico bastante adaptado.

$\mathrm{O}$ modo de atração dos visitantes por meio de odor intenso, o comportamento dos mesmos e a diferença de tempo na descarga de pólen entre os indivíduos, sugere que possa existir um tipo de adaptação no sistema de polinizaçấo da espécie, pois, se dois indivíduos da espécie, que estejam próximos, tiverem uma diferença na hora de liberação do pólen, é bastante provável que os insetos que saiam das flores do indivíduo, onde o término da antese ocorra mais cedo e, atraídos pelo odor, possam alcançar as flores de um segundo indivíduo ainda receptivo, eventualmente transferindo pólen.

O conjunto de estratégias que a flor apresenta (emissão de odor noturna, tipo de odor, pétalas carnosas etc.) confere a ela uma síndrome de cantarofilia.

Isto indica que os besouros Chrysomelidae que visitam as flores, com dimensões adequadas ao tamanho das mesmas, são os que possuem maior probabilidade de ter sucesso na sua polinização. As moscas, por terem tamanho reduzido e comportamento menos padronizado, parecem ser pouco eficientes na transferência de pólen, mas podem ocasionalmente funcionar como polinizadores acessórios.

A baixa frutificação verificada em Annona sericea Dun. nas condições estudadas pode ser devida à não ocorrência de indivíduos em áreas próximas, ou por falta de transferência adequada de pólen.

\section{Agradectmentos}

Agradeço à Dra. Judy M. Rankin, ao Dr. Gerhard Gottsberger e aos M.Sc. Pedro Ivo S. Braga e Marilene M. Nogueira Braga pela leitura do manuscrito e pelas sugestões dadas.

\section{SUMMARY}

This paper presents the basic characteristic of the floral biology of Annona sericea Dun. Observations were based on five adult trees located on the INPA Campus in Manaus, AM. The flowers of Annona sericea Dun. are cantharophilous with the temperature of the flower rising to $6^{\circ} \mathrm{C}$ above of nighttime temperature. Insect visitors observed were beetles of the family Chrysomelidae (likely pollinators) and flies of the family Sciaridae (occasional pollinators). The beetles feed on the internal parts of the petals and also mate inside the flowers. The synchronous shedding of the stigmas and subsequent dehiscence of the anthers on any given plant precludes the possibility of self-pollination both at the level of the flower and individual tree however the species is self-compatible. Pollen fertility is $96 \%$, however the natural fruit-set is very low.

\section{REFERÊNCIAS BIBLIOGRÁFICAS}

DARLINGTON, C.D. \& LA COUR, L.F.

1965 - The handling of chromosomes. apud. Sharma, A.K. \& Sharma, A. 1972 - Chromosome Techniques 2. ed. Butterworths University Park Press.

GOTTSBERgER, G.

1970 - Beiträge zur Biologie von Annonaceen- Blüten. Österr. Bot. Z., 118: 237-279.

LocQuin, M.V.

1975 - Natural color guide. In: Taxa Fungorum.

PERIASAMY, K.

1954 - On the floral biology of some members of the Anonaceae. J. Madras Univ., B, 1: 7-12.

PIJL, L. VAN DER

1953 - On the flower biology of some plants from Java. Ann. Bogor., 1: 77-99.

Prance, G.T. \& ARIAS, J.R.

1975 - A study of the Floral Biology of Victoria amazonica (Poepp.) Sowerby (Nymphaeceae). Acta Amazonica, 5 (2): 109-139.

WALKER, J.W.

1971 - Pollen morphology, phytogeography and phylogeny of the Annonaceae. Contributions from the Gray Herbarium, 202: 1-130.

(Aceito para publicaçăo em $20 / 08 / 80$ ) 